\title{
ĐÁNH GIÁ HIÊUU QUẢ GIẢM ĐAU SAU PHẪU THUÂT LẤY THAI BẰNG KỸ THUÂT GẦY TÊ CO' VUÔNG THẮT LƯNG DƯớI HƯỚNG DẪN CỦA SIÊU ÂM TẠI BỆNH VIÊ̂N ĐA KHOA QUỐC TẾ VINMEC PHÚ QUỐC
}

\author{
Nguyễn Xuân Tịnh*, Phạm Thiều Trung*, Vũ Đức Định*
}

\section{TÓM TẮT}

Muc tiêu: Đánh giá hiêu quả giảm đau sau mổ lấy thai bằng kỹ thuật gây tể cơ vuông thắt lưng dưới hướng dấn của siêu âm; Tìm hiểu một số tác dụng không mong muốn çủa kỹ thuật gây tề cơ vuông thắt lưng dưới hướng dẫn của siêu âm. Phương pháp: Nghiên cứu tiến cứu can thiệp, mô tả cắt ngang, không đối chứng. Kết quả: Về hiệu quả và thời gian giảm đau: Thời gian bắt đâu tác dụng giảm đau trung bình 12,68 $\pm 86,02$ phút. Thời gian thuốc có tác dụng giảm đau: Từ 0 - 5giờ: $06 \%$; Từ 6 - 10 giờ: $18 \%$; Tù̀ 11 - 15 giờ: 26\%; Từ 16 - 20giờ: $12 \%$; Từ 20 giờ trở lên: $38 \%$. Hiệu quả giảm đau sau mô lấy thai bằng phương pháp gây tê cơ vuông thắt lưng ở mức độ rất tốt và tốt là $100 \%$. Thời gian tác dụng giảm đau kéo dài $16,12 \pm 6,82$ giờ, (ii) Tác dụng phu của thuốc và tai biến của kỹ thuât: Không có tai biển, biến chứng nào nghiêm trơng. Tác dụng phụ buồn nôn, nôn là $3 \%$; lanh run là $5 \%$. Kết liuấn: Gây tê cơ vuông thắt lưng để giảm đau sau mổ lấy thai rất có hiệu quả và an toàn cho sản phụ.

Tư khóa: Giảm đau, phẫu thuật lấy thai, gây tê cơ vuông thắt lưng, hướng dấn bằng siêu âm

\section{SUMMARY \\ EVALUATING THE EFFECTIVENESS OF PAIN RELIEF AFTER CASAREAN SECTION BY USING ULTRASOUND-GUIDED QUADRATUS LUMBORUM BLOCK PROCEGURE}

Objectives: To evaluate the effectiveness of pain relief after cesarean section by using ultrasoundguided quadratus lumborum block procedure; To learn some undesirable effects of this technique. Methods: An interventional, cross-sectional, prospective, noncontrolled study. Results: Regarding the effectiveness and duration of analgesia: The average time of onset of analgesic effect was $12.68 \pm 86.02$ minutes. Time the drug has an analgesic effect: From 0 to 5 hours: $06 \%$; From 6 to 10 hours: $18 \%$; From 11 am to 3 pm: $26 \%$; From 16 to 20 hours: 12\%; From 20 hours or more: $38 \%$. The effectiveness of pain relief after cesarean section by the method of anesthesia of ultrasound-guided quadratus lumborum block is at a very good and good level of $100 \%$. The duration of analgesic effect lasted $16.12 \pm 6.82$ hours, (ii) Side effects of the drug and at the time of technique: There were no serious complications or complications.

*Bệnh viện $Đ K$ QT Vinmec Phú Quốc Chịu trách nhiệm chính: Vũ Đức Định Email: drvuducdinh@gmailcom Ngày nhận bài: 21/8/2021

Ngày phản biện khoa học: 20/9/2021

Ngày duyệt bài: $1 / 10 / 2021$
Side effects nausea, vomiting is 3\%; shivering is $5 \%$. Conclusion: Anesthesia of the lumbar squamous muscle to relieve pain after cesarean section is very effective and safe for post cesarean women.

Keyword: Pain relief, cesarean section, quadratus lumborum block procedure, ultrasound-guided.

\section{I. ĐĂT VẤN ĐỀ}

Đau sau mổ là nỗi sợ hãi, ám ảnh của nhiều bệnh nhân, đặc biệt là đau sau phẫu thuật lấy thai. Đau nhiều sau mổ sẽ ảnh hưởng đến tâm sinh lý cũng như sự phục hồi của sản phụ sau mổ. Kiểm soát tốt đau sau phẫu thuật giúp sản phụ vận động sớm hơn, giảm thời gian nằm viện, giảm viện phí, nâng cao sự hài lòng của người bệnh.

Hiện nay có nhiều phương pháp giảm đau sau phẫu thuật lây thai như gây tê ngoài màng cứng, gây tê cớ vuông thắt lưng, thuốc truyền tĩnh mạch, tiêm bắt thuốc giảm đau, thuốc đặt hậu mồn, thuốc dán, thuốc uống...[2]. Phương pháp giảm đau sau mổ lấy thai bằng kỹ thuật gây tê cơ vuông thắt lưng dưới sự hướng dẫn của siêu âm là một kỹ thuật mới, tác dụng hiệu quả giảm đau rất tốt và an toàn cho sản phụ[2], [3].

Tại Bệnh viện đa khoa quốc tế Vinmec Phú Quốc hàng năm tiến hành rất nhiều ca phẫu thuật mổ lấy thai và chúng tôi đã áp dụng nhiều phương pháp giảm đau sau phẫu thuật cho thai phụ trong đó có kỹ thuật gây tê cơ vuông thắt lưng. Để góp phần vào việc đánh giá ưu nhược điểm của phương pháp này, chúng tôi tiến hành nghiên cứu:

"Đánh giá hiệu quả giảm đau sau phẫu thuật lấy thai bằng kỹ thuật gây tê cơ vuông thắt lưng dưới hướng dẫn của siêu âm tại Bệnh viện đa khoa quốc tế Phú Quốc" với mục tiêu:

- Đánh giá hiệu quả giảm đauu sau mổ lây thai bằng kỹ thuật gây tê cơ vuông thắt lưng dưới hướng dẫn của siêu âm

- Tim hiểu một số tác dụng không mong muốn của kỹ thuật gây tê cơ vuông thắt lưng dưới hướng dẫn của siêu âm.

\section{II. ĐỐI TƯỢNG VÀ PHƯƠNG PHÁP NGHIÊN CỨU}

2.1. Đối tượng nghiên cứu: Tất cả các thai phụ được chỉ định phầu thuật lấy thai từ tháng 11 -2019 đênn hết tháng 06 - 2020.

\subsubsection{Tiêu chuẩn chọn}


- Sản phụ sau mổ lấy thai ASA I-II.

- Không có chống chỉ định gây tê vùng.

- Đã được khám gây mê trước và được giải thích trước mổ về kỹ thuật gây tê cơ vuông thắt lung.

- Được đánh giá thang điểm VAS > 3.

- Các xét nghiệm huyết học, chức năng đông máu giới hạn bình thường.

- Sản phụ đồng ý làm thủ thuật.

\subsubsection{Tiêu chuẩn loại}

- Nhiễm trùng tại vùng chọc kim gây tê.

- Bệnh nhân có tiền sử dị ứng thuốc tê.

- Tiền sử rối loạn tâm thần, khó khăn trong giao tiếp, đánh giá mức độ đau.

- Sản phụ không hợp tác.

- Rối loạn đông máu hay đang điều trị thuốc chống đông máu.

2.2. Thiết kế nghiên cứu: Nghiên cứu tiến cứu can thiêp, mô tả cắt ngang, không đối chứng

- Cõ̃ mấu tính theo công thức:

$\mathrm{n}=z^{2} \frac{p(1-p)}{c^{2}}$

Điều kiện: $\mathrm{nf}>10$; $\mathrm{n}(1-\mathrm{f})>10$

Trong đó: $\mathrm{n}$ : Cở mẫu nhỏ nhất hợp lý

z: 1,96 với trị số mức độ tin cậy mong muốn là $95 \%$; c: sai số cho phép 0,05 với độ tin cậy 95\%; p: 0,93 là tî lệ giảm đau thành công theo nghiên cứu của Lê Anh Tuấn Bệnh viện phụ sản Hà Nội [4] thay vào công thức trên, cỡ mẫu nghiên cứu tính được là: $n=101,8$ trường hợp, tính tròn mẫu là 100.

- Địa điểm nghiên cứu: Phòng mổ - Khoa Ngoại Tổng Hợp Bệnh viện Đa khoa Vinmec Phú Quốc Tỉnh Kiên Giang.

\subsection{Trang thiết bị, thuốc}

2.3.1. Trang thiết bi

- Máy siêu âm chuyên dụng.

- Mơm tiêm điện, máy truyền dịch, vật tư tiêu hao các loại.

2.3.2. Thuốc. Thuốc sử dụng Ropivacain 0,5\%. Tên biệt dược Anaropin $5 \mathrm{mg} / \mathrm{ml}$. Ông tiêm $10 \mathrm{ml}$ chứa Ropivacaine Hydrochloride $50 \mathrm{mg}$. Quy cách đóng gói: Anaropin $5 \mathrm{mg} / \mathrm{ml}$ được đóng gói Hộp 5 ống x 10 ml. Số đăng ký: VN2-10413. Thời han sử dung: Sử dung thuốc trong thời hạn 36 tháng kể từ ngày sản xuất. Thuốc được sản xuất tại AstraZeneca AB-Thụy Điển.

2.4. Xử lý số liệu: Sử dụng phần mềm Stata 12.0

\section{KẾT QUẢ NGHIÊN CứU VÀ BÀN LUÂ̂N \\ 3.1. Một số thông số chung}

3.1.1.Tuổi, cân nặng, chiều cao. Qua 100 trường hợp sản phụ được can thiệp giảm đau sau mổ lấy thai bằng phương pháp gây tê cơ vuông thắt lưng dưới hướng dẫn siêu âm cho thấy độ tuổi trung bình là $25,03 \pm 4,75$ tuổi. Phân chia theo nhóm tuổi cho thấy trong mẫu nghiên cứu sản phụ nằm trong độ tuổi sinh đẻ từ 20 đến 30 tuổi chiếm tỷ lệ $76 \%$. Kết quả này cũng tương tự như trong nghiên cứu của các tác giả Lê Anh Tuấn [4] Nguyển Tất Bình [1] với độ tuổi sinh đẻ là sinh lý bình thường của phụ nữ.

Cân nặng trung bình của thai phụ là $60,82 \pm$ $7,57 \mathrm{~kg}$. Trong đó cân nặng nhóm nghiên cứu từ $51 \mathrm{~kg}$ đến $60 \mathrm{~kg}$ chiếm tỷ lệ cao nhất $44 \%$, cân nặng thấp nhất là $49 \mathrm{~kg}$ và cao nhất là $82 \mathrm{~kg}$. Phân bố cân nặng và cân nặng trung bình cũng tương tự như trong nghiên cứu của Lê Anh Tuấn [4] với cân nặng trung bình là $57,6 \mathrm{~kg}$; cân nặng thấp nhất là $42 \mathrm{~kg}$ và cao nhất là $77 \mathrm{~kg}$.

Theo kết quả số liệu của mẫu nghiên cứu với cân nặng trung bình là $60,82 \pm 7,57$ kg, tính ra được chỉ số khối cơ thể (BMI) trung bình là 25,47. Như vậy mẫu nghiên cứu các sản phụ có vẻ có nguy cớ béo phì. Đặc biệt, nhóm các thai phụ có cân nặng trên $60 \mathrm{~kg}$ là nhóm có nguy cơ béo phì độ 1 theo thống kê chiếm tỷ lệ $50 \%$ là không nhỏ. Tuy nhiên, khi phân tích thống kê cho thấy các nhóm cân nặng không ảnh hưởng lên các kết quả giảm đau.

Trong nghiên cứu chúng tôi nhận thấy chiều cao trung bình của mẫu nghiên cứu là $154,5 \mathrm{~cm}$ $\pm 6,2$ Chiêu cao tối thiểu là $148 \mathrm{~cm}$ và tối đa là $168 \mathrm{~cm}$. Nhóm chiều cao từ $150 \mathrm{~cm}$ đến $160 \mathrm{~cm}$ chiếm tỷ lệ cao nhất đến $93 \%$. Phân tích thống kê cho thây không có khác biệt có ý nghĩa về chiều cao trung bình của những tác giả khác $[5,6,7]$.

3.1.2. Tiên sử mổ lấy thai. Trong kết quả nghiên cứu, tỷ lệ phẫu thuật lấy thai lần đầu chiếm $55 \%$, mổ lấy thai lần 2 trở lên chiếm $45 \%$, Phân tích thống kê cho thấy không có khác biệt có ý nghĩa thống kê với các nghiên cứu khác.

Với kết quả này, khi so sánh các biến số trong hiệu quả giảm đau sau mổ lần đầu ít đau hơn các sản phụ mổ lần hai trở lên, có thể do mổ lần hai mức độ dầy dính các tạng, phẫu thuật viên bóc tách nhiều hơn, nên mức độ đau sau mồ nhiều hơn các sản phụ mổ lấy thai lần đầu là điều dễ hiểu. Trong các nghiên cứu của các tác giả Nguyễn Tất Bình[1], Lê Anh Tuấn [4] cũng đều có tỷ lệ con so cao hơn con rạ

\subsubsection{Liêuu lượng thuốc sử dụng}

Liều 15ml/bên Anaropin 0,5\% chiếm 89\% ở những sản phụ có cân nặng > 50Kg; Liều $12 \mathrm{ml} /$ bên Anaropin 0,5\% chiếm $08 \%$ ở những sản phụ có cân nặng $40-50 \mathrm{Kg}$; Liêu $10 \mathrm{ml} /$ bên Anaropin $0,5 \%$ chiểm $03 \%$ ở những sản phụ có cân nặng $<40 \mathrm{Kg}$; liều trung bình theo khuyến 
cáo của nhà sản xuất thuốc tê Ropivacaine cho phép dùng liều trung bình $3-4 \mathrm{mg} / \mathrm{kg}$ thì chúng tôi sử dụng liều $3 \mathrm{mg} / \mathrm{kg}$ và cũng là phác đồ điều trị của Bệnh viện Đa khoa quốc tê Vinmec Time City cũng như các bệnh viện khác. Trong các nghiên cứu của các tác giả Nguyễn Tất Bình [1], Lê Anh Tuấn [4] cũng dùng liều tương tự

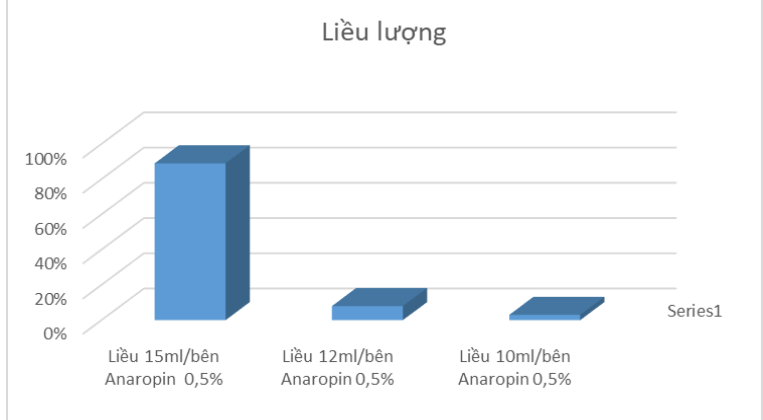

Biểu đồ 3.1. Liều các thuốc sử dụng 3.2. Hiệu quả giảm đau

\subsubsection{Thời gian bắt đâu tác dụng:}

Bắt Đầu Tác Dụng

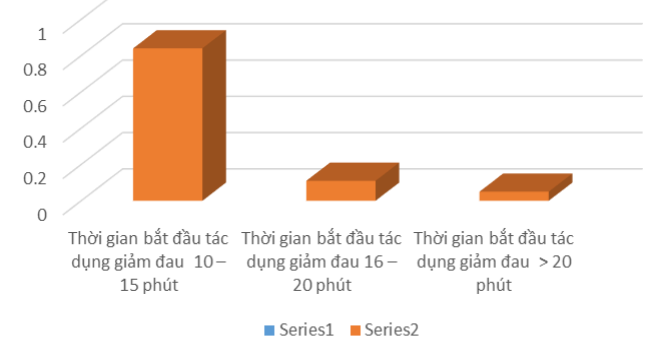

Biểu đồ 3.2. Thời gian bắt đầu có tác dụng giảm đau

Thời gian bắt đầu tác dụng giảm đau 10-15 phút sau khi gây tê chiếm $84 \%$; Thời gian bắt đầu tác dụng giảm đau 16-20 phút sau khi gây tê chiếm 11\%; Thời gian bắt đầu tác dụng giảm đau > 20 phút sau khi gây tê chiếm $05 \%$; Thời gian bắt đầu tác dụng giảm đau trung bình 12,68 $\pm 86,02$ phút; Trong các nghiên cứu của các tác giả Tạ Quang Hùng[3], Lề Anh Tuấn [4] cũng thời gian bắt đầu tác dụng tương tự như nghiên cứu của chúng tôi.

\subsubsection{Mức đô giảm đau}

Bảng 3.1. Mức độ giảm đau

\begin{tabular}{|c|c|c|}
\hline Tác dụng giảm đauu & Số lượng & Tỷ lệ \% \\
\hline Rất tốt VAS = & 97 & 97 \\
\hline Tốt VAS = 1 & 3 & 3 \\
\hline
\end{tabular}

Trong nghiên cứu của chúng tôi, để đánh giá hiệu quả giảm đau của phương pháp gây tê cơ vuông thắt lưng sau mổ lấy thai, chúng tôi sử dụng thang điểm đau VAS (Visual Analogue
Scale) và thang điểm Wong-Baker Công cụ này là một thước đo có hai mặt. Mặt dành cho thai phụ có 05 hình mă̆t người biểu thị các trạng thái từ không đau đên đau không chịu nổi. Mặt sau có chia khoảng cách như một thang điểm đánh số từ 0 đến 10 để thầy thuốc lượng giá tương ứng với các mức độ đau. Giảm đau hoàn toàn ( 0 điểm), còn đau nhe (1-3 điểm), đau vừa (4-6 điểm), đau nhiều (7 - 8 điểm) và còn đau rất nhiều (9 - 10 điểm). Đây là công cụ được nhiều nghiên cứu lựa chọn vì dễ sử dụng do sản phụ nhìn bằng mắt thường các hình ảnh diễn tả vẻ mặt của sản phụ ứng với các mức độ đau, sản phụ chỉ việc chọn hình vẽ diễn đạt nào mà mình cảm thấy phù hợp nhất. Trong khi đó người thầy thuốc thông qua vẻ mặt của sản phụ sẽ đánh giá theo thang điểm [6]. Kết quả trong nghiên cứu này có $97 \%$ được giảm đau gần như hoàn toàn, $03 \%$ còn đau nhẹ, còn đau vừa và đau nhiêu không có trường hợp nào. Qua đó cho thấy hiệu quả của giảm đau ở đề tài $97 \%$ là không đau và đau nhẹ 03\%. Phương pháp gây tê cơ vuông thắt lưng thật sự có tác dụng giảm đau rất tốt sau mổ lấy thai.

Trong nghiên cứu này, chúng tôi cũng thực hiện đánh giá khả năng giảm đau tương tự như trong nghiên cứu của một số tác giả $[4],[6,7]$. Trong khi thực hiện giảm đau, chúng tôi nhờ sản phụ nhận xét xem mức độ đau đã được cải thiện như thể nào, ở vết mổ trên thành bụng, phẩn biệt với cơn đau do sự co hồi của tử cung, giúp ước lượng mức tê trên và dưới vị trí làm thủ thuật gây tê cũng như bên phải hay bên trái (sự không đối xứng) và mức tê theo thời gian.

Theo kết quả nghiên cứu mức giảm đau ở mức không đau và đau nhẹ so với nghiên cứu của Nguyễn Tất Bình [1] là $96 \%$ và mức đau từ 0 đến 3 điểm, cũng tương tự như trong nghiên cứu của Lê Anh Tuấn [4] là $92,1 \%$. Sự khác biệt về tỷ lệ giảm đau có hiệu quả của phương pháp gây tê cơ vuông thắt lựng trong các nghiên cứu có thể do kỹ thuật và kinh nghiệm gây tê không hoàn toàn giống nhau giứa các nghiên cứu nhưng nhìn chung khả năng giảm đau có hiệu quả đạt tỷ lệ cao và hoàn toàn có thể xem như đây là phương pháp giảm đau có hiệu quả tốt để ứng dụng trong thực tế lâm sàng.

\subsubsection{Thời gian tác dụng giảm đau}

Bảng 3.2. Thời gian tác dụng giảm đau

\begin{tabular}{|c|c|c|}
\hline $\begin{array}{c}\text { Thời gian tác dụng } \\
\text { giảm đau }\end{array}$ & $\begin{array}{c}\text { Số } \\
\text { lượng }\end{array}$ & Tỷ lệ \% \\
\hline Từ $0-5$ giờ & 06 & $06 \%$ \\
\hline Từ $6-10$ giờ & 18 & $18 \%$ \\
\hline Từ $11-15$ giờ & 26 & $26 \%$ \\
\hline
\end{tabular}




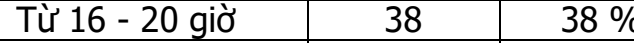

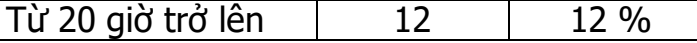

Trong nghiên cứu của chúng tôi thời gian tác dụng giảm đau sau mổ lấy thai bằng kỹ thuật gẩy tê cơ vuông thắt lưng dưới hướng dẫn của siêu âm hiệu quả tác dụng giảm đau kéo dài thời gian trung bình $16,12 \pm 6,82$. Thời gian tác dụng ngắn nhất là 04 giờ, dài nhất 24 giờ. Trong khi các nghiên cứu của các tác giả: 14,88 \pm 8,26 [5] và $15,82 \pm 7,12 \%[7]$. Sự khác biệt về thời gian tác dụng giảm đau của các tác giả không có ý nghĩa thống kê, nhưng có thể khẳng định một điều là phương pháp gây tê cơ vuông thắt lưng có tác dụng giảm đau kéo dài thời gian hơn so với các phương pháp gây tê một liều khác.

\subsection{Môt số tác dung phụ}

Bảng 3.3. Một số tác dụng phụ

\begin{tabular}{|c|c|c|}
\hline Biến chứng & $\begin{array}{c}\text { Số trường } \\
\text { hợp }\end{array}$ & $\begin{array}{c}\text { Tỷ lệ } \\
\mathbf{\%}\end{array}$ \\
\hline Dị ứng, ngộ độc thuốc tê & 00 & 00 \\
\hline Chảy máu và tụ máu tại chồ & 00 & 00 \\
\hline Hạ huyết áp, suy hô hấp & 00 & 00 \\
\hline Buồn nôn, nôn ói & 03 & 3 \\
\hline Lạnh run & 05 & 5 \\
\hline
\end{tabular}

Trong nghiên cứu của chúng tôi có 03 trường hợp buồn nôn và nôn ói ở mức độ ít sau khi gây tể 30 - 45 phút chiếm tỷ lệ $03 \%$. Chúng tôi đã cho sản phụ nằm đầu cao, thở oxy qua mũi 4 lít/phút, hướng dẫn sản phụ hít thở sâu sau đó tự khỏi. Tìm hiểu kỹ được biết 3 sản phụ này chưa nhịn ăn uống đủ 6 giờ trước khi mổ lấy thai cấp cứu khẩn với phương pháp vô cảm là gây mê nội khí quản. Khi so với nghiên cứu của tác giả Tạ Quang Hùng [3] và Nguyễn Tất Bình [1], là $3,82 \%$ và $03 \%$ cho thây tỷ lệ biến chứng này xảy ra không đáng kể.

Chúng tôi có 05 trường hợp sau khi gây tê bị lạnh run ở mức độ ít và trung bình chiếm tỷ lệ 05\%. Nguyên nhân gây ra lạnh run sau khi gây tê có thể do sản phụ thiếu máu, trải quả cuộc phẫu thuật mở ở phòng lạnh, và đôi khi do gẩy tê tủy sống trước đó để vô cảm trong mổ lây thai: chúng tôi sưởi ấm thông thường triệu chứng lạnh run thoáng qua và đã tự khỏi 03 trường hợp, tuy nhiên có 02 trường hợp triêu chứng này kéo dài hơn 15-20 phút sản phụ vẩn không hết lạnh run chúng tôi xử trí thuốc Pethidine $25 \mathrm{mg}$ tiêm tĩnh mạch theo phác đồ chống lạnh run do gây tê tủy sống sau 5-7 phút sản phụ hết lạnh run.

Các biến chứng khác như di ứng, ngộ độc thuốc tê, suy hô hấp, tụt huyết áp...chúng tôi không gặp trường hợp nào.

\section{KẾT LUẬN}

4.1. Về hiệu quả và thời gian giảm đau. Thời gian bắt đầu tác dụng giảm đau 10-15 phút sau khi gây tê chiếm $84 \%$; Thời gian bắt đầu tác dụng giảm đau 16-20 phút sau khi gây tê chiếm $11 \%$; Thời gian bắt đầu tác dụng giảm đau > 20 phút sau khi gây tê chiếm $05 \%$; Thời gian bắt đầu tác dụng giảm đau trung bình 12,68 \pm 86,02 phút.

Thời gian thuốc có tác dụng giảm đau: Từ 0 5 giờ: $06 \%$; Từ 6 - 10 giờ: 18\%; Từ 11 - 15 giờ: $26 \%$; Từ 16 - 20 giờ: $12 \%$; Từ 20 giờ trở lên: $38 \%$.

Hiệu quả giảm đau sau mổ lấy thai bằng phương pháp gây tê cơ vuông thắt lưng ở mức độ rất tốt và tốt là $100 \%$. Thời gian tác dụng giảm đau kéo dài $16,12 \pm 6,82$ giờ.

4.2. Tác dụng phụ của thuốc và tại biến của kỹ thuật. Trong đề tài chúng tôi không có tai biến, biển chứng nào nghiêm trọng... Tác dụng phụ buồn nôn, nôn là 3\%; lạnh run là $5 \%$.

\section{KHUYẾN NGHI}

Tiếp tục thực hiện phương pháp này tại bênh viện Đa khoa Quốc tế Vinmec Phú Quốc để vô cảm sau sinh mổ cho sản phụ tại đây.

\section{TÀI LIÊU THAM KHẢO}

1. Nguyễn Tất Bình (2019), "Kỹ thuâat gây tê vùng mới trong giảm đau sau mổ lây thai. Kinh nghiệm bước đâu gây tê khoang cơ vuông thắt lưng dưới hướng dẫn siêu âm qua 50 trường hợp", Kỷ yếu Hội nqhị GMHS TP Hồ Chí Minh, Tr. 66-69.

2. Nguyên Văn Chinh (2010), "Giảm đau sau mô", Đai Hoc Y Dước TP. HCM.

3. Tạ Quang Hừng (2020), "Nhận xét tác dụng giảm đảu sau mổ lấy thai của phương pháp gây tê cơ vuông thắt lưng hai bên", tạp chí y học TP Hồ Chí Minh, 4(23), Tr. 118-123.

4. Lê Anh Tuấn (2019), "Đánh giá hiệu quả giảm đau sau mổ lấy thai bằng phương pháp gây tê cơ vuông thắt lưng dưới hướng dẫn siêu âm", Tạp chí Nghiên cứu Y học, 9(20), Tr. 14-23.

5. Hîronobu Ueshima et al (2017), "UltrasoundGuided Quadratus Lumborum Block: An Updated Review of Anatomy and Techniques", Biomed research International, 10(1155), pp. 20-25.

6. Abeer Ahmed, Maher Fawzy et al (2019), "Ultrasound-guided quadratus lumborum block for postoperative pain control in patients undergoing unilateral inguinal hernia repair, a comparative study between two approaches", BMC Anesthesiology, 19(184), pp. 234-237.

7. Gudny E Steingrimsdottir, Gunnar Hellmund Laier et al, (2019), "Ultrasound-guided transmuscular quadratus lumborum block for elective cesarean section significantly reduces postoperative opioid consumption and prolongs time to first opioid request: a double-blind randomized trial", Regional Anesthesia and Pain Medicine, 9(44), pp. 23-29. 